\title{
Teratoma sacrococcígeo neonatal em felino: relato de caso
}

\section{Sacrococcygeal teratoma neonatal feline: case report}

\author{
Fernanda Vieira Henrique ${ }^{1 *}$; Angélica Ramalho de Araújo Leite ${ }^{1}$; \\ Carla Lauise Rodrigues Menezes Pimenta ${ }^{1}$; Almir Pereira de Souza ${ }^{2}$; \\ Priscila Maria Silva do Carmo ${ }^{3}$; Antônio Flávio Medeiros Dantas ${ }^{2}$
}

\begin{abstract}
Resumo
Teratomas são tumores embrionários benignos formados por diferentes tipos de tecidos derivados das três camadas germinativas, encontrados mais comumente nos ovários e testículos, principalmente em equinos e humanos. Relata-se um caso de teratoma ocorrido em um felino de três meses de idade, macho e sem raça definida. Clinicamente, o animal apresentava um aumento de volume de $13 \times 7,0$ x 4,0 cm de extensão de superfície lisa e áreas firmes e flutuantes na base da cauda, de crescimento progressivo, observado pelo proprietário desde o nascimento. Ao exame radiográfico da cauda foram observadas áreas radiopacas distribuídas de forma difusa em toda extensão da massa tumoral. $\mathrm{O}$ animal foi submetido à exérese da massa e o material foi encaminhado para o exame histopatológico onde foi diagnosticado teratoma. $\mathrm{O}$ animal recuperou-se do procedimento cirúrgico que é o único tratamento preconizado nesse caso.
\end{abstract}

Palavras-chave: Cirurgia, gato, histopatologia, tumor embrionário

\begin{abstract}
Teratomas are embryonal benign tumors formed by different types of tissues derived from the three germ layers, found most commonly in the ovaries and testicles, mainly in horses and humans. It is reported a case of teratoma occurred in a cat of three months of age, male and mongrel. Clinically the animal showed increase of volume of $13 \times 7.0 \times 4.0 \mathrm{~cm}$ extension of smooth and firm and floating areas in the base of the tail, observed by owner from birth and progressive growth. In the radiographic examination of the tail were observed radiopaque areas diffusely distributed on the entire tumor mass. The animal was undergoing excision of the mass and the material was sent for histopathological examination which was diagnosed teratoma. The animal recovered from surgery, which is the only treatment recommended in this case.
\end{abstract}

Key words: Surgery, cat, histopathology, embryonal tumor

\footnotetext{
${ }^{1}$ Discentes de Mestrado do Programa de Pós-Graduação da Universidade Federal de Campina Grande, UFCG, Centro de Saúde e Tecnologia Rural, campus de Patos, PB.E-mail: nandinhavh@gmail.com; angelica_ral@yahoo.com.br; carlalauise@hotmail. com

${ }^{2}$ Profs. Drs. da Unidade Acadêmica de Medicina Veterinária, UFCG, campus de Patos, PB. E-mail: almirpsouza@ibest.com.br; dantas.af@uol.com.br

${ }^{3}$ Discente de Doutorado do Programa de Pós-Graduação UFCG, campus de Patos, PB. E-mail: priscilamcarmo@gmail.com

* Autor para correspondência 


\section{Introdução}

Os teratomas são neoplasias originadas de células germinativas totipotenciais, compostas pelas três camadas embrionárias (endoderme, mesoderme e ectoderme), apresentando-se, císticos, semicísticos ou sólidos (BLASZAK et al., 2009). Nos tumores mais diferenciados podem ser identificados diversos tipos de tecidos, tais como, dentes, cartilagem, mucosa intestinal, tecido cutâneo, neuronal e adiposo (FRIEDLICH; SHIN; SERI, 2006). Devido à origem celular germinativa as regiões mais acometidas por essas neoplasias são os ovários e os testículos (LEFEBVRE et al., 2005).

Esses tumores ocorrem mais comumente em equinos e humanos (LEFEBVRE et al., 2005), sendo que na espécie humana o teratoma sacrococcígeo é um dos tumores mais comuns em neonatos, desenvolvendo-se, geralmente, na porção anterior da região sacrococcígea e se estendendo ao espaço retroperitoneal, virilha, ânus e glúteos (GABRA et al., 2006).

Os teratomas são neoplasias benignas sendo que teratomas malignos são raros em animais (VANHAESEBROUCK et al., 2010) diferindo da espécie humana onde os teratomas malignos são encontrados com maior frequência (JONES; HUNT; KING, 1997).

O diagnóstico de teratoma é realizado através de laparotomia exploratória, exames radiográficos, análise histopatológica ou achados de necropsia (GOETHEM; BOSMANS; CHIERS, 2010). Em relação ao tratamento preconiza-se a ressecção cirúrgica completa. Devido a se tratar de uma neoplasia benigna, não ocorre recidiva após a exérese, determinando assim um bom prognóstico (JATENE et al., 2008). Em cães tem sido relatado um tempo de sobrevida de até 6 anos após a ressecção cirúrgica de teratomas gonadais (GREENLEE; PATNAIK, 1985).

Objetivou-se com esse relato, registrar um caso de teratoma localizado na região da cauda em um felino jovem.

\section{Relato de Caso}

Um felino, sem raça definida (SRD), macho, com três meses de idade, pesando $0,400 \mathrm{~kg}$, foi atendido no Hospital Veterinário do Centro de Saúde e Tecnologia Rural (CSTR) da Universidade Federal de Campina Grande (UFCG) Campus de Patos/PB, apresentando um aumento de volume na base da cauda, o qual, segundo o proprietário, foi observado desde o nascimento apresentando crescimento progressivo (Figura 1). Clinicamente, o animal apresentava-se apático, estado nutricional ruim, mucosas pálidas e desidratação moderada.

Foram solicitadas radiografias do tórax e da região sacrococcígea. $\mathrm{Na}$ avaliação radiográfica torácica não foram observadas alterações. A radiografia da região da cauda revelou áreas de radiopacidade distribuídas difusamente em toda a extensão da massa.

Foi realizada a punção aspirativa por agulha fina para realização de exame citológico, onde foram observados diversos tipos celulares com predomínio de queratinócitos, obtendo-se resultado inconclusivo.

O animal foi tratado durante uma semana com suplementos vitamínicos e minerais e alimentação hipercalórica até melhora do estado clínico geral. Posteriormente, o paciente foi encaminhado para o setor de cirurgia para remoção da massa. O material foi fixado em formol a $10 \%$ e encaminhado para análise histopatológica no Laboratório de Patologia Animal do CSTR/UFCG. 
Figura 1. Felino, SRD, três meses de idade, com teratoma sacrococcígeo.

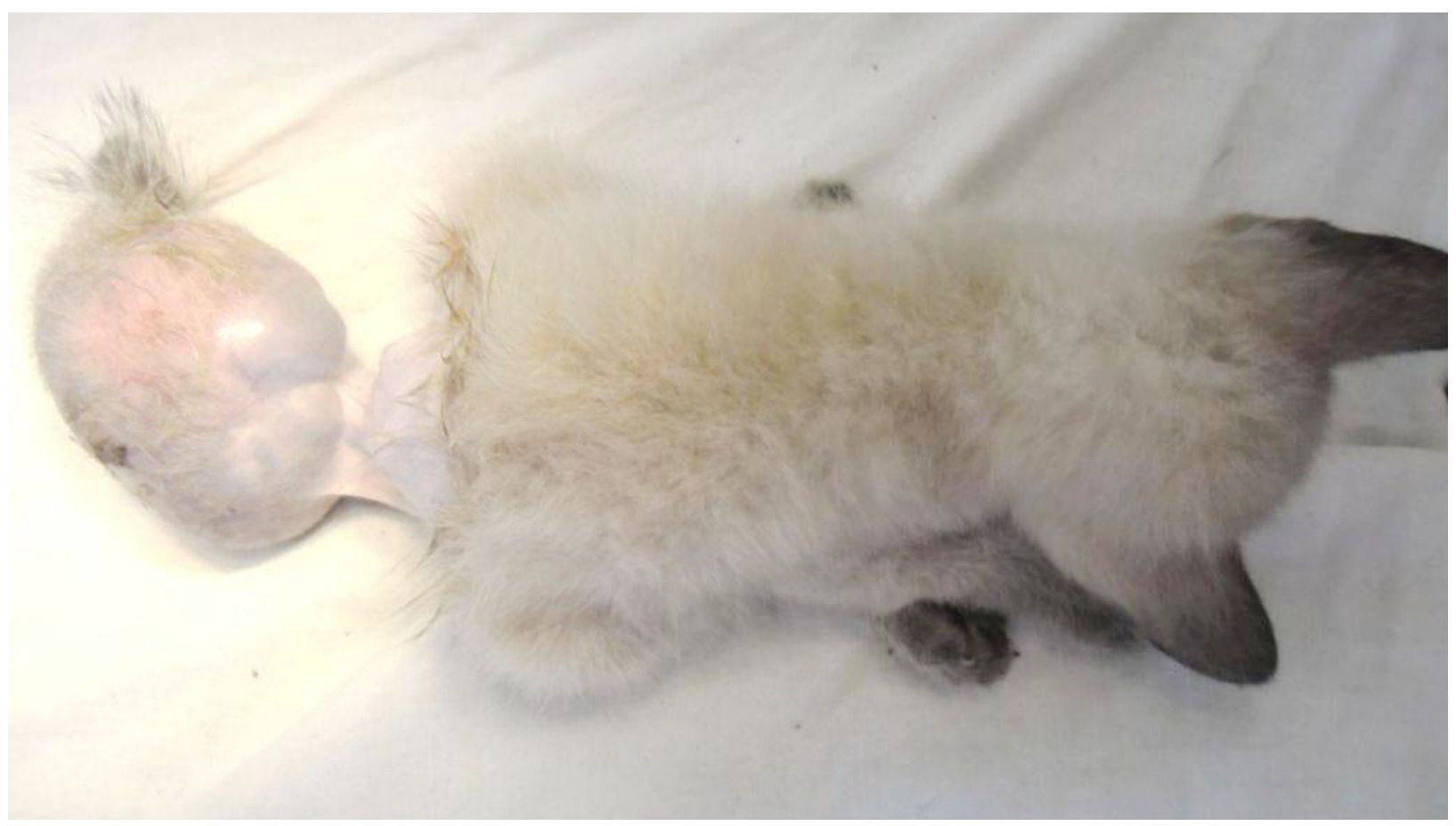

Fonte: Elaboração dos autores.

$\mathrm{Na}$ avaliação macroscópica observou-se uma massa de $13 \times 7 \times 4 \mathrm{~cm}$, de formato arredondado, com superfície lisa e consistência variável entre áreas firmes ou flutuantes. Ao corte a massa era branca e irregular com múltiplos focos formados por tecido de consistência endurecida. Microscopicamente, observou-se uma proliferação neoplásica constituída por tipos teciduais originados das três camadas de células germinativas primordiais. Havia áreas sólidas compostas de tecido neural (neuropila) moderadamente celular com neurônios e oligodendrócitos. Verificou-se também a formação de alguns gânglios nervosos compostos por células nervosas ganglionares circundadas por células satélites (Figura 2 Ac). Havia áreas compostas por epiderme (epitélio pavimentoso estratificado) e seus anexos (Figura 2 Babc). Por vezes, observouse formação de osteoide (Figura $2 \mathrm{Ab}$ ) e de matriz condroide (Figura $2 \mathrm{Bd}$ ). Adicionalmente, observaram-se focos de tecido epitelial cilíndrico simples, mucoso e ciliado (Figura 2 C). Esses achados no exame histopatológico confirmaram o diagnóstico de teratoma. 
Figura 2. Microfotografia de teratoma sacrococcígeo em felino. A) a - Tecido medular; b - Trabéculas ósseas; c Tecido nervoso; d - Tecido adiposo. HE; 10X. B) a - Epiderme; b - Folículos pilosos; c - Glândula sebácea; d - Tecido cartilaginoso. HE; 20X. C) Tecido epitelial cilíndrico ciliado, observar células caliciformes (a) e cílios (b). HE; 40X.

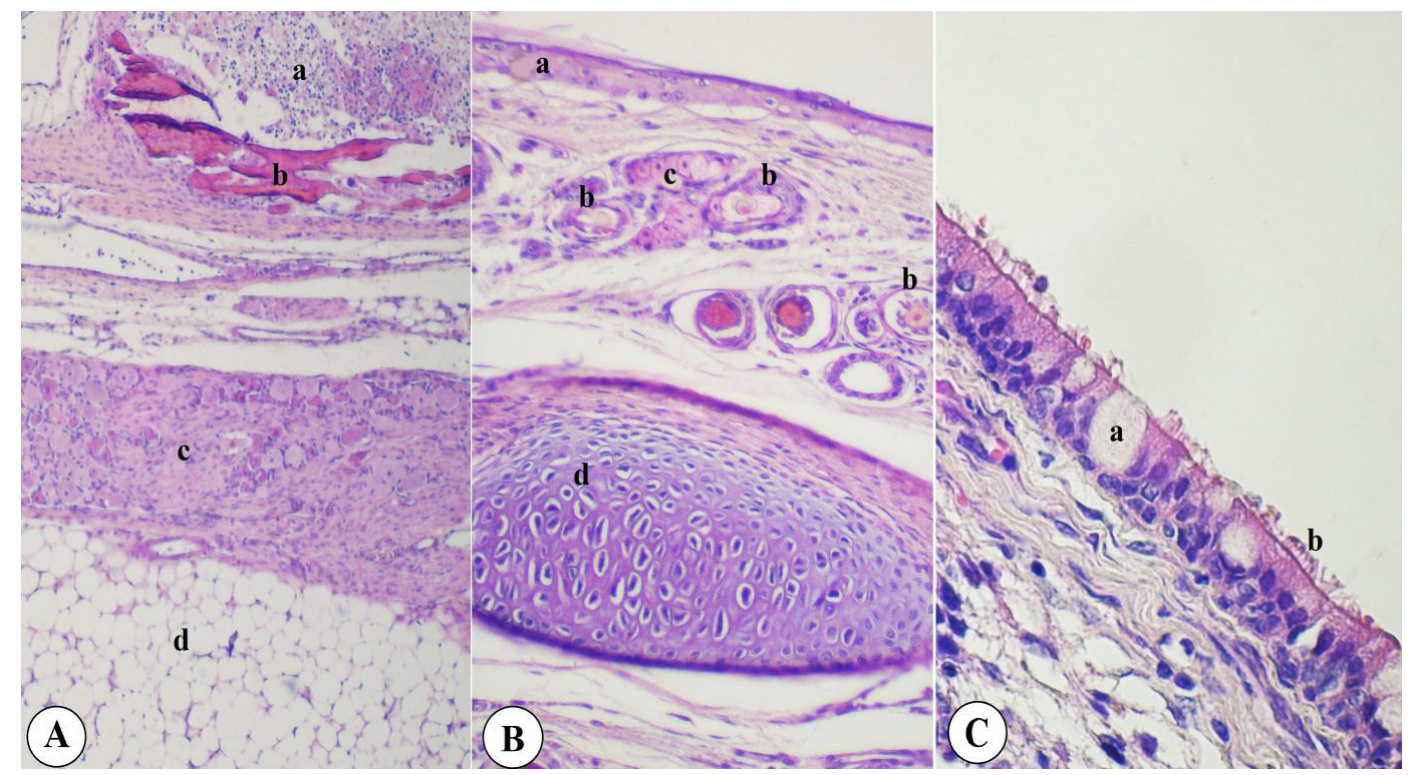

Fonte: Elaboração dos autores.

\section{Discussão}

Este relato descreve um teratoma em um felino de três meses de idade. Segundo Goethem, Bosmans e Chiers (2010) a média de idade deste tipo de neoplasia em felinos é de três anos, diferindo do caso em estudo que se trata de um animal jovem com desenvolvimento congênito e que, por se tratar de um teratoma extragonadal, foi percebido mais precocemente pelo proprietário.

Em humanos, teratomas sacrococcígeos correspondem a $69 \%$ dos casos de neoplasias neonatais e localizam-se entre o cóccix e o reto (GABRA et al., 2006), assim como no caso aqui relatado, onde a neoplasia abrangeu a região sacral caudal, as vértebras coccígeas e o ânus.

$\mathrm{Na}$ radiografia da região da cauda observaramse focos radiopacos distribuídos difusamente, indicativos de mineralização como os achados no estudo de Goethem, Bosmans e Chiers (2010).

O exame citológico não foi suficiente para diagnosticar o tipo de tumor, assim como no caso descrito por Goethem, Bosmans e Chiers (2010). O predomínio de queratinócitos no caso relatado concorda com Bertazzolo et al. (2004) que afirmam que, dependendo do local onde for realizada a punção, pode haver predomínio de um único tipo celular.

O diagnóstico de teratoma foi realizado através do exame histopatológico, onde foi observada a presença de tecido neural e epidérmico, além de formação de osteóide e de matriz condroide, evidenciando a presença dos três folhetos germinativos, concordando com Bishop (1978) que afirma que a classificação de um tumor como um teratoma depende da presença de tecidos derivados de pelo menos duas linhagens germinativas e evidência de crescimento progressivo.

Os achados histopatológicos indicaram que se tratava de uma neoplasia benigna já que os tecidos observados eram bem diferenciados e não havia características de malignidade (SANTOS et al., 2007; BLASZAK et al., 2009). 


\section{Conclusão}

Esterelato registra o aparecimento de um teratoma extragonadal em um filhote felino, mostrando que, apesar de raro em pequenos animais, o teratoma pode se apresentar na região sacrococcígea. $O$ método de diagnóstico mais eficaz nestes casos é o exame histopatológico. O tratamento cirúrgico tem potencial curativo quando é realizada a ressecção completa do tumor.

\section{Referências}

BERTAZZOLO, W.; DELL'ORCO, M.; BONFANTI, U.; DELORENZI, D.; MASSERDOTTI, C.; DE MARCO, B.; CANIATTI, M.; ROCCABIANCA, P. Cytological features of canine ovarian tumours: a retrospective study of 19 cases. The Journal of small animal practice, Grã Bretanha, v. 45, n. 11, p. 539-545, 2004.

BISHOP, L. Intracranial teratoma in a domestic rabbit. Veterinary Pathology, Cary, v. 15, n. 4, p. 525-530, 1978.

BLASZAK, B.; WALKOWSKI, M.; IBBS, M.; JASKOWSKI, J. M. Teratoma adultum in a bitch: a case report. Veterinarni Medicina, Prague, v. 54, n. 8, p. 379$381,2009$.

FRIEDLICH, P.; SHIN, C. E.; SERI, I. Cardiovascular compromise in the surgical neonate. Seminars in Anesthesia, Perioperative Medicine and Pain, Philadelphia, v. 25, n. 3, p. 124-135, 2006.

GABRA, H. O.; JESUDASON, E. C.; MCDOWELL, H. P.; PIZER, B. L.; LOSTY, P. D. Sacrococcigeal teratoma - a 25 year experience in a UK regional center. Journal of Pediatric Surgery, Philadelphia, v. 41, n. 9, p. 15131516, 2006.
GOETHEM, B. V.; BOSMANS, T.; CHIERS, K. Surgical resection of a mature teratoma on the head of a young cat. Journal of the American Animal Hospital Association, Lakewood, v. 46, n. 2, p.121-126, 2010.

GREENLEE, P. G.; PATNAIK, A. K. Canine ovarian tumors of germ cell origin. Veterinary Pathology, Cary, v. 22, n. 2, p. 117-122, 1985.

JATENE, M. B.; ABUCHAIM, D.; MARTINS, L.; BARBERO-MARCIAL, M. Tratamento cirúrgico de teratoma intrapericárdico em lactente. Revista Brasileira de Cirurgia Cardiovascular, São José do Rio Preto, v. 23, n. 1, p. 123-125, 2008.

JONES, T. C.; HUNT, R. D.; KING, N. W. Disturbances of growth: aplasia to neoplasia. In: . Veterinary pathology. 6. ed. Baltimore: Lippincott Willian \& Wilkins, 1997. p. 81-112.

LEFEBVRE, R.; THEORET, C.; DORÉ, M.; GIRARD, C.; LAVERTY, S.; VAILLANCOURT, D. Ovarian teratoma and endometritis in a mare. The Canadian Veterinary Journal, Ottawa, v. 46, n. 11, p. 1029-1033, 2005.

SANTOS, P. C.; MAIA, C. P.; PEREIRA, J. C. P.; OLIVEIRA, T. C. A. Teratoma gigante de mediastino: achado cirúrgico pós-trauma torácico. Revista Brasileira de Cirurgia Cardiovascular, São José do Rio Preto, v. 22, n. 2, p. 252-254, 2007.

VANHAESEBROUCK, E.; GOVAERE, J.; SMITS, K.; DURIE, I.; VERCAUTEREN, G.; MARTENS, A.; SCHAUVLIEGE, S.; DUCATELLE, E.; HOOGEWIJS, M.; DE SCHAUWER, C.; KRUIF, A. Ovarian teratoma in the mare: a review and two cases. Vlaams Diergenees kundig Tijdschrift, Bélgica, v. 79, n. 1, p. 32-41, 2010. 
